\title{
TO COMPARE THE HAEMODYNAMIC RESPONSE TO LARYNGOSCOPY AND TRACHEAL INTUBATION USING THE STANDARD MACINTOSH LARYNGOSCOPE VERSUS VIDEOLARYNGOSCOPE AMONG HEALTHY ADULT INDIVIDUALS RECEIVING GENERAL ANAESTHESIA FOR ELECTIVE SURGERY
}

\author{
Utsav Sharma1, Preeti Goyal2, Anju Gautam³, Bhanu Chaudhary ${ }^{4}$
}

${ }^{1}$ Senior Resident, Department of Anaesthesiology, Gajra Raja Medical College, Gwalior, Madhya Pradesh, India.

2 Professor, Department of Anaesthesiology, Gajra Raja Medical College, Gwalior, Madhya Pradesh, India.

${ }_{3}^{3}$ Associate Professor, Department of Anaesthesiology, Gajra Raja Medical College, Gwalior, Madhya Pradesh, India.

4 Professor and HOD, Department of Anaesthesiology, Gajra Raja Medical College, Gwalior, Madhya Pradesh, India.

\section{BACKGROUND}

ABSTRACT

Laryngoscopy and endotracheal intubation are associated with various undesirable effects. The more common response to airway manipulation is hypertension (HTN) and tachycardia mediated by the cardioaccelerator nerves and sympathetic chain ganglia. Numerous efforts have been made by anaesthesiologists to obtund these untoward reflexes by the use of various measures such as by using drugs or by using different methods of intubation.

\section{MATERIALS AND METHODS}

100 patients of either sex of ASA grade I and II and Mallampati grade I and II of age 18 - 60 years were included in the study. Patients $<18$ years of age and $>60$ years of age and Mallampati grade III and IV were excluded from the study. A standard anaesthesia technique was used in all the patients. Both groups were matched demographically. Haemodynamic variables at baseline were also comparable.

\section{RESULTS}

It was observed that rise in pulse rate, systolic blood pressure, diastolic blood pressure and mean BP was significantly less in videolaryngoscope group as compared to Macintosh group $(\mathrm{p}<0.01)$.

\section{CONCLUSION}

It was concluded that videolaryngoscope produces significantly less marked haemodynamic response.

\section{KEY WORDS}

Macintosh Laryngoscope, Truview PCD Videolaryngoscope, Mean Pulse Rate, Mean Systolic Blood Pressure, Mean Diastolic Blood Pressure.

HOW TO CITE THIS ARTICLE: Sharma U, Goyal P, Gautam A, et al. To compare the haemodynamic response to laryngoscopy and tracheal intubation using the standard Macintosh laryngoscope versus videolaryngoscope among healthy adult individuals receiving general anaesthesia for elective surgery. J. Evolution Med. Dent. Sci. 2018;7(41):4450-4456, DOI: $10.14260 /$ jemds/2018/993

\section{BACKGROUND}

Laryngoscopy and endotracheal intubation are an integral part of anaesthetic management. Infact, most of the advances made by our specialty can be attributed to manage the airway. The first known description on the surgical procedure of intubation was given in the 1020 by Ibn Sīnā in "The Canon of Medicine" in order to facilitate breathing.(1),(2)

Like all the interventional procedures, laryngoscopy and endotracheal intubation are associated with various undesirable effects. In adults and adolescents, the more common response to airway manipulation is hypertension (HTN) and tachycardia mediated by the cardioaccelerator nerves and sympathetic chain ganglia including release of renin from the renal juxtaglomerular apparatus, which is innervated by $\beta$-adrenergic nerve terminals.(2)

'Financial or Other Competing Interest': None.

Submission 25-08-2018, Peer Review 21-09-2018,

Acceptance 27-09-2018, Published 08-10-2018.

Corresponding Author:

Dr. Preeti Goyal,

Professor, Department of Anaesthesiology,

Gajra Raja Medical College, Gwalior, Madhya Pradesh, India.

E-mail: drpreetiravigoyal@gmail.com

DOI: $10.14260 /$ jemds $/ 2018 / 993$

\section{(c) $($ ) $\$$}

Reflex changes in cardiovascular system are most marked after laryngoscopy and intubation and lead to average increase in blood pressure by $40-50 \%$ and heart rate by $20 \%$.(3) These reflex changes are better tolerated in normotensive and healthy individuals with no systemic diseases. But they are greatly exaggerated and detrimental in patients with hypertension and cardiovascular diseases even if treated and brought under control beforehand.(4-7) In patients with head injury, cerebral autoregulation is disturbed and increase in heart rate and blood pressure may result in increase in cerebral blood flow and therefore rise in ICP.(8)

Numerous efforts have been made in this direction. Anaesthesiologists have been trying to obtund these untoward reflexes by the use of various measures such as:Curtailing or shortening the duration of laryngoscopy to less than 15 seconds. Lightwand technique is accompanied by less haemodynamic changes after tracheal intubation than the laryngoscopic technique in normotensive patients, but not in hypertensive patients.(8)

Use of McCoy laryngoscope and laryngeal mask airway is associated with minimum stress response to laryngoscopy and intubation as compared to Macintosh and Miller laryngoscopy. $(9,10)$ Videolaryngoscope does not need direct exposure of vocal cords and produces lesser haemodynamic 
changes due to the reduction in the lifting force necessary to obtain a clear view of the glottis. It provides an optical view "around the corner," allowing a view of the glottis via the prismatic lens without having to align oral, pharyngeal and tracheal axes.(11)

This prospective randomised study was conducted to compare the haemodynamic response to laryngoscopy and tracheal intubation using the standard Macintosh laryngoscope versus Videolaryngoscope.

\section{Aims and Objectives}

1. To compare the haemodynamic response to laryngoscopy and tracheal intubation using the standard Macintosh laryngoscope versus Videolaryngoscope among healthy adult individuals receiving general anaesthesia for elective surgery.

2. Complications of laryngoscopy with Macintosh and Videolaryngoscope.

\section{MATERIALS AND METHODS}

It is a randomised controlled trial. After obtaining approval from the Ethical Committee, the present double blind study entitled "To compare the haemodynamic response to laryngoscopy and tracheal intubation using the standard Macintosh laryngoscope versus videolaryngoscope" was conducted on patients of ASA grade I and II in 100 number of patients of either sex, Department of Anaesthesiology, JA Group of Hospitals of GR Medical College, Gwalior (MP) after a well written informed consent from the patients. This prospective study was conducted from Dec. 2015 to Aug. 2017.

Patients of ASA grade I and II, age $>18$ years of either sex and Mallampati grade I and II were included for the study. Patients of ASA grade III and IV; Mallampati grade III and IV; history of hypertension, cardiovascular disease, difficulty with mask ventilation during anaesthesia were excluded from the study.

100 patients of ASA grade I and II of either sex scheduled for surgery under general anaesthesia were divided into 2 groups, $(n=50$ each) randomly according to the type of laryngoscope. Sample size was taken for convenience during the study.

They were randomised using computer generated random numbers and allocated into two groups, Group $\mathrm{M}$ and Group A used as follows: Group M patients were intubated with Macintosh Laryngoscope and Group A with Videolaryngoscope.

All patients were uniformly pre-medicated with Inj. Glycopyrrolate $0.01 \mathrm{mg} / \mathrm{kg}$ IM 30 minutes before induction of anaesthesia.

Upon arrival of the patient in the operation room, intravenous access with 18G cannula was established. 500 $\mathrm{mL}$ of crystalloid infusion was started. All the baseline vital parameters (HR, SBP, DBP, MAP) were recorded. Oxygen saturation (SPO2) were recorded by using pulse oximeter.

Patients were pre-oxygenated with $100 \%$ oxygen for 3 minutes by facemask. After premedication with IV Inj. Pentazocine $0.5 \mathrm{mg} / \mathrm{kg}$, general anaesthesia was induced with IV Inj. Thiopentone Sodium $5-7 \mathrm{mg} / \mathrm{kg}$ body weight, Endotracheal intubation was facilitated with IV Inj. Succinylcholine $1.5-2.0 \mathrm{mg} / \mathrm{kg}$ bodyweight, after which IPPV was done for 60 seconds. Laryngoscopy and intubation was done in 'Morning Sniff' position with Macintosh laryngoscope and in neutral position with Videolaryngoscope. In our study, we use Macintosh Laryngoscope Blade No. 3 and Truview PCD videolaryngoscope Blade No. 3.

Endotracheal tube checked, cuff inflated and well secured. Bilateral air entry checked, and the lung was ventilated further.

General anaesthesia was maintained with nitrous oxide and oxygen (66:33) and Isoflurane (1 - 1.5\%) with Bain's anaesthetic circuit. Loading and intermittent dosage of nondepolarising muscle relaxant atracurium were used to maintain general anaesthesia.

All the haemodynamic parameters Heart Rate (HR), Systolic Blood Pressure (SBP), Diastolic Blood Pressure (DBP), Mean Arterial Pressure (MAP) and Oxygen Saturation $\left(\mathrm{SPO}_{2}\right)$ were recorded 30 seconds before induction (Io), at the time of laryngoscopy and intubation $\left(E_{0}\right), 1$ minute $\left(E_{1}\right), 2$ minutes $\left(E_{2}\right), 3$ minutes $\left(E_{3}\right)$ and 5 minutes $\left(E_{5}\right)$ after endotracheal intubation.

\section{Laryngoscopes used in Our Study 1. Macintosh Laryngoscope}

Macintosh introduced his curved blade, while most laryngoscope blades were long and straight. The straight blades were used to directly hold the epiglottis. Macintosh's curved blade works differently. It indirectly opens the epiglottis by applying pressure to a space between the root of the tongue and epiglottis called the vallecula. The flange running along the left lower edge of Macintosh's blade was also a novel innovation. It was designed to move the tongue to the side, which improved the view of the larynx and made more room for a breathing tube. The Macintosh Laryngoscope remains one of the most popular blades worldwide.

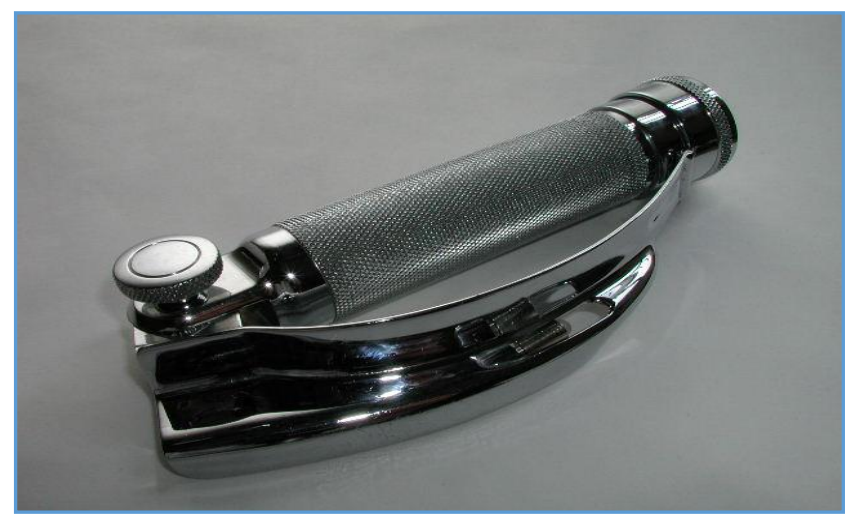

Figure 1. Macintosh Laryngoscope

\section{Truview PCD Videolaryngoscope}

It consists of reusable stainless steel blades, a view tube, an oxygen insufflation port, a camera head that attaches to the proximal part of the view tube, a handle that provides the light source and a portable (5.5" battery-powered) monitor. The distal lens is essentially a prism with a 47-degree anterior view. The proximal lens magnifies the acquired image.

1. Monitor, 2. Dedicated Camera, 3. Rechargeable Handle, 4. Eyepiece, 5. Oxygen Port, 6. Optical View Tube (Distal End), 7. 
Optical View Tube Blade (Distal tip), 8. OptiShapeTM Preformed Stylet.

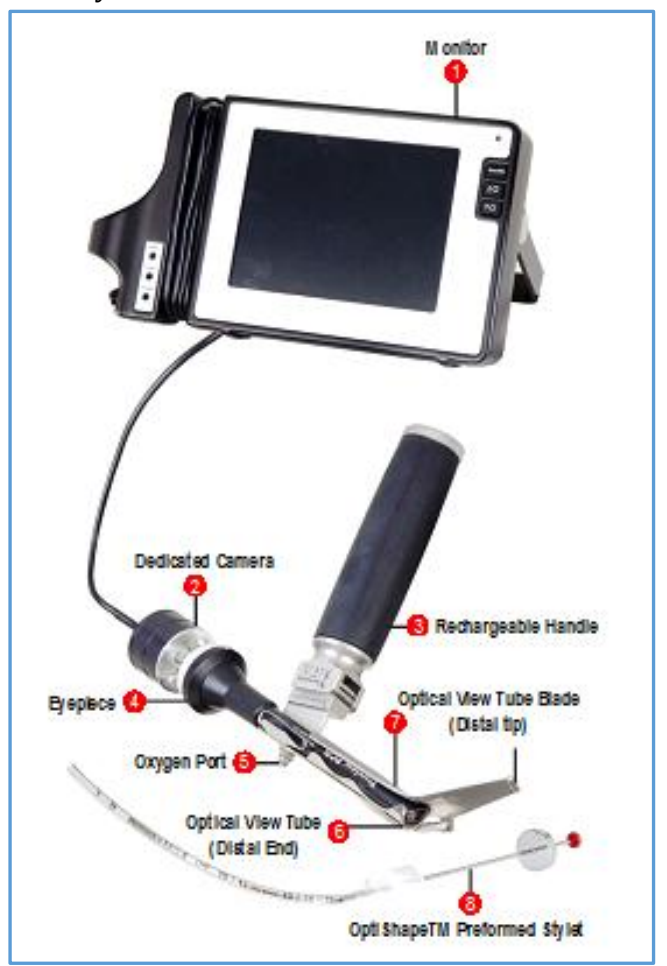

Figure 2. Truview PCD Videolaryngoscope

\section{How to Use the Device}

The device is held in left hand and passed into the mouth over the tongue in the midline. Blade connected to a dedicated 5in. LCD monitor via a unique camera for obtaining clear visual pictures of the intubation process. In this way, clinical safety is greatly improved and the incidence of incorrectly positioned endotracheal tube is reduced. The addition of oxygen during the intubation procedure via the unique oxygen port on the blades serves to slow the rate of desaturation, prevents the accumulation of mist and secretions on the lenses and ensures a clear visual picture of the entire procedure. Videolaryngoscope is a device with a unique blade that provides an optical view of the glottis via prismatic lens without having to align oral, pharyngeal and tracheal axes.

\section{Statistical Analysis}

The statistical analysis of this study was carried out by unpaired ' $t$ ' test and also paired ' $t$ ' test, where $p$ value $<0.05$ was statistically significant and $\mathrm{p}$ value $>0.05$ was statistically insignificant and $p$ value $<0.01$ was statistically highly significant. Software used was SPSS version 21 .

\section{RESULTS}

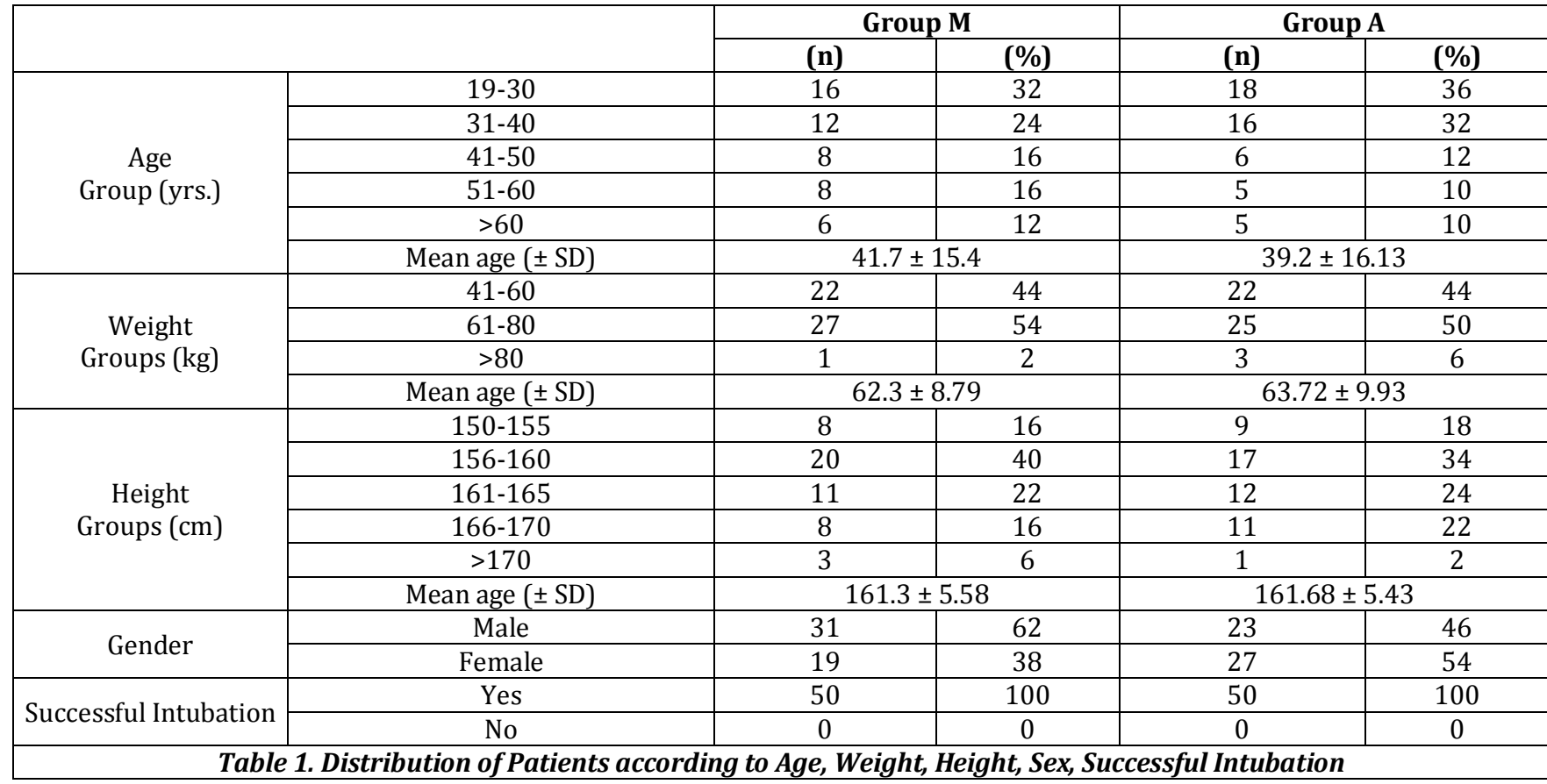

\begin{tabular}{|c|c|c|c|c|c|c|}
\hline Sl. No. & $\begin{array}{c}\text { Time } \\
\text { (min) }\end{array}$ & $\begin{array}{c}\text { Group M } \\
\text { (Mean } \pm \text { SD) }\end{array}$ & $\begin{array}{c}\text { Group M } \\
\text { (p-value) }\end{array}$ & $\begin{array}{c}\text { Group A } \\
\text { (Mean } \pm \text { SD) }\end{array}$ & $\begin{array}{c}\text { Group A } \\
\text { (p-value) }\end{array}$ & $\begin{array}{c}\text { Group M v/s } \\
\text { Group A } \\
\text { (p-value) }\end{array}$ \\
\hline 1 & $\mathrm{I}_{0}$ & $82 \pm 8.8$ & -- & $84.7 \pm 12.28$ & -- & 0.3370 \\
\hline 2 & $\mathrm{E}_{0}$ & $92.04 \pm 11.25$ & 0.0001 & $87 \pm 13.49$ & 0.0100 & 0.0452 \\
\hline 3 & $\mathrm{E}_{1}$ & $99.89 \pm 10.08$ & 0.0001 & $87.56 \pm 12$ & 0.0020 & 0.0001 \\
\hline 4 & $\mathrm{E}_{2}$ & $95.26 \pm 9.84$ & 0.0001 & $82.08 \pm 12.21$ & 0.0302 & 0.0001 \\
\hline 5 & $\mathrm{E}_{3}$ & $89.18 \pm 8.94$ & 0.0006 & $79.84 \pm 12.62$ & 0.0003 & 0.0001 \\
\hline 6 & $\mathrm{E}_{5}$ & $82 \pm 9.67$ & 0.9379 & $76.48 \pm 12.54$ & 0.0001 & 0.0151 \\
\hline \multicolumn{7}{|c|}{} \\
\hline
\end{tabular}




\begin{tabular}{|c|c|c|c|c|c|c|}
\hline Sl. No. & $\begin{array}{l}\text { Time } \\
(\mathrm{min})\end{array}$ & $\begin{array}{c}\text { Group M } \\
(\text { Mean } \pm \text { SD) }\end{array}$ & $\begin{array}{l}\text { Group M } \\
\text { (p-value) }\end{array}$ & $\begin{array}{c}\text { Group A } \\
\text { (Mean } \pm \text { SD) }\end{array}$ & $\begin{array}{c}\text { Group A } \\
\text { (p-value) }\end{array}$ & $\begin{array}{c}\text { Group M v/s } \\
\text { Group A } \\
\text { (p-value) }\end{array}$ \\
\hline 1 & $\mathrm{I}_{0}$ & $117.42 \pm 10.78$ & -- & $119.28 \pm 13.21$ & -- & 0.4423 \\
\hline 2 & $\mathrm{E}_{0}$ & $131.44 \pm 9.36$ & 0.0001 & $122.26 \pm 14.22$ & 0.0001 & 0.0002 \\
\hline 3 & $E_{1}$ & $134.10 \pm 10.28$ & 0.0001 & $120.16 \pm 12.78$ & 0.4057 & 0.0001 \\
\hline 4 & $E_{2}$ & $123.75 \pm 10.69$ & 0.0004 & $114.88 \pm 11.97$ & 0.0006 & 0.0002 \\
\hline 5 & $E_{3}$ & $116.30 \pm 10.24$ & 0.3639 & $110.04 \pm 10.25$ & 0.0001 & 0.0029 \\
\hline 6 & $E_{5}$ & $110.91 \pm 9.16$ & 0.0001 & $105.56 \pm 10.84$ & 0.0001 & 0.0090 \\
\hline
\end{tabular}

\begin{tabular}{|c|c|c|c|c|c|c|}
\hline Sl. No. & $\begin{array}{l}\text { Time } \\
\text { (min) }\end{array}$ & $\begin{array}{c}\text { Group M } \\
(\text { Mean } \pm \text { SD) }\end{array}$ & $\begin{array}{l}\text { Group M } \\
\text { (p-value) }\end{array}$ & $\begin{array}{c}\text { Group A } \\
(\text { Mean } \pm \text { SD) }\end{array}$ & $\begin{array}{c}\text { Group A } \\
\text { (p-value) }\end{array}$ & $\begin{array}{c}\text { Group M v/s } \\
\text { Group A } \\
\text { (p-value) }\end{array}$ \\
\hline 1 & $\mathrm{I}_{0}$ & $73.97 \pm 6.26$ & -- & $75.76 \pm 8.70$ & -- & 0.2405 \\
\hline 2 & $E_{0}$ & $80.88 \pm 13.79$ & 0.0019 & $78.3 \pm 8.33$ & 0.0001 & 0.2602 \\
\hline 3 & $\mathrm{E}_{1}$ & $83.14 \pm 7.82$ & 0.0001 & $76.88 \pm 8.65$ & 0.1904 & 0.0003 \\
\hline 4 & $E_{2}$ & $77.37 \pm 7.25$ & 0.0035 & $73.66 \pm 6.28$ & 0.0512 & 0.0074 \\
\hline 5 & $E_{3}$ & $74.14 \pm 5.59$ & 0.8608 & $71.04 \pm 5.58$ & 0.0005 & 0.0066 \\
\hline 6 & $\mathrm{E}_{5}$ & $71.53 \pm 4.43$ & 0.0067 & $69.26 \pm 6.14$ & 0.0001 & 0.0365 \\
\hline
\end{tabular}

\begin{tabular}{|c|c|c|c|c|c|c|}
\hline Sl. No. & $\begin{array}{c}\text { Time } \\
\text { (min) }\end{array}$ & $\begin{array}{c}\text { Group M } \\
\text { (Mean } \pm \text { SD) }\end{array}$ & $\begin{array}{c}\text { Group M } \\
\text { (p-value) }\end{array}$ & $\begin{array}{c}\text { Group A } \\
\text { (Mean } \pm \text { SD) }\end{array}$ & $\begin{array}{c}\text { Group A } \\
\text { (p-value) }\end{array}$ & $\begin{array}{c}\text { Group M v/s } \\
\text { Group A } \\
\text { (p-value) }\end{array}$ \\
\hline 1 & $\mathrm{I}_{0}$ & $88.18 \pm 7.10$ & -- & $89.58 \pm 9.60$ & -- & 0.4091 \\
\hline 2 & $\mathrm{E}_{0}$ & $98.71 \pm 7.36$ & 0.0001 & $92.94 \pm 9.66$ & 0.0001 & 0.0011 \\
\hline 3 & $\mathrm{E}_{1}$ & $99.77 \pm 7.88$ & 0.0001 & $91.02 \pm 9.12$ & 0.1231 & 0.0001 \\
\hline 4 & $\mathrm{E}_{2}$ & $92.42 \pm 7.45$ & 0.0005 & $87.18 \pm 7.69$ & 0.0567 & 0.0008 \\
\hline 5 & $\mathrm{E}_{3}$ & $87.85 \pm 5.81$ & 0.7079 & $83.32 \pm 5.99$ & 0.0001 & 0.0002 \\
\hline 6 & $\mathrm{E}_{5}$ & $84.32 \pm 5.06$ & 0.0001 & $80.82 \pm 6.79$ & 0.0001 & 0.0043 \\
\hline \multicolumn{6}{r}{} \\
\hline
\end{tabular}

\begin{tabular}{|c|c|c|}
\hline Variable & Group M & Group A \\
\hline Complications & Nil & Nil \\
\hline
\end{tabular}

As shown in table, no complications were observed in both the groups.

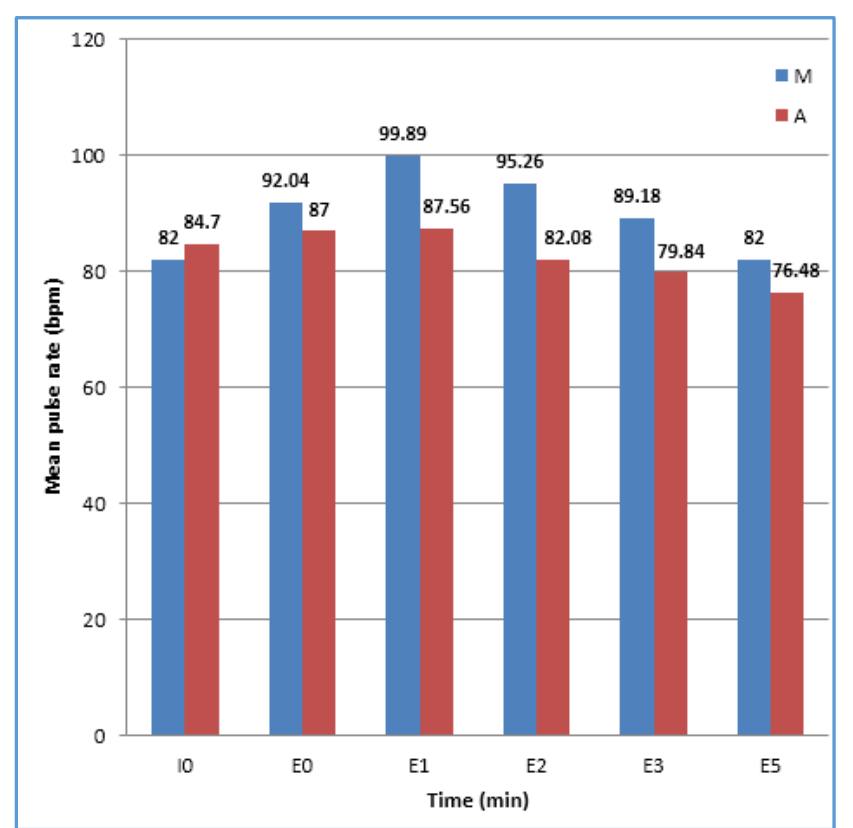

Graph 1. Statistical Analysis of Mean Pulse Rate (bpm) between the Two Study Groups

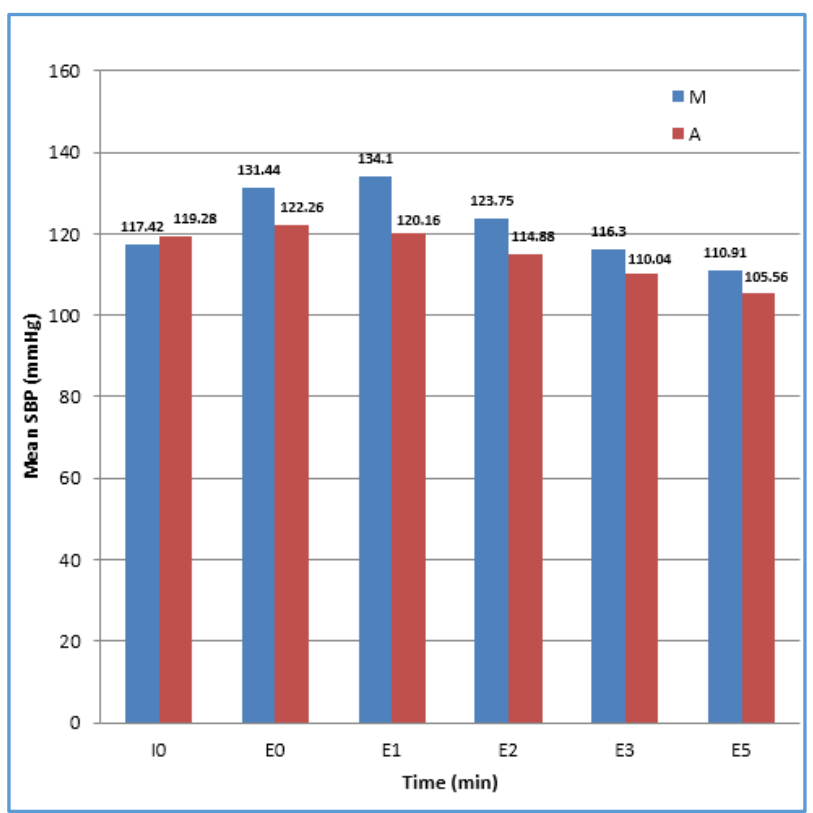

Graph 2. Statistical Analysis of Mean Systolic Blood Pressure ( $\mathrm{mmHg}$ ) between the Two Study Groups 


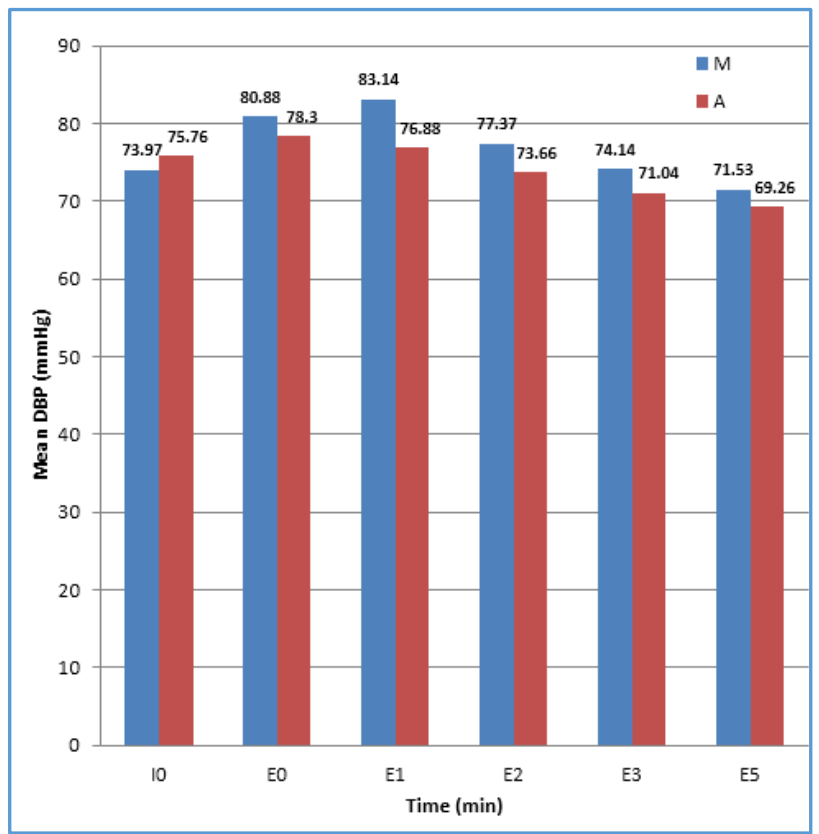

Graph 3. Statistical Analysis of Mean Diastolic Blood Pressure ( $\mathrm{mmHg}$ ) between the Two Study Groups

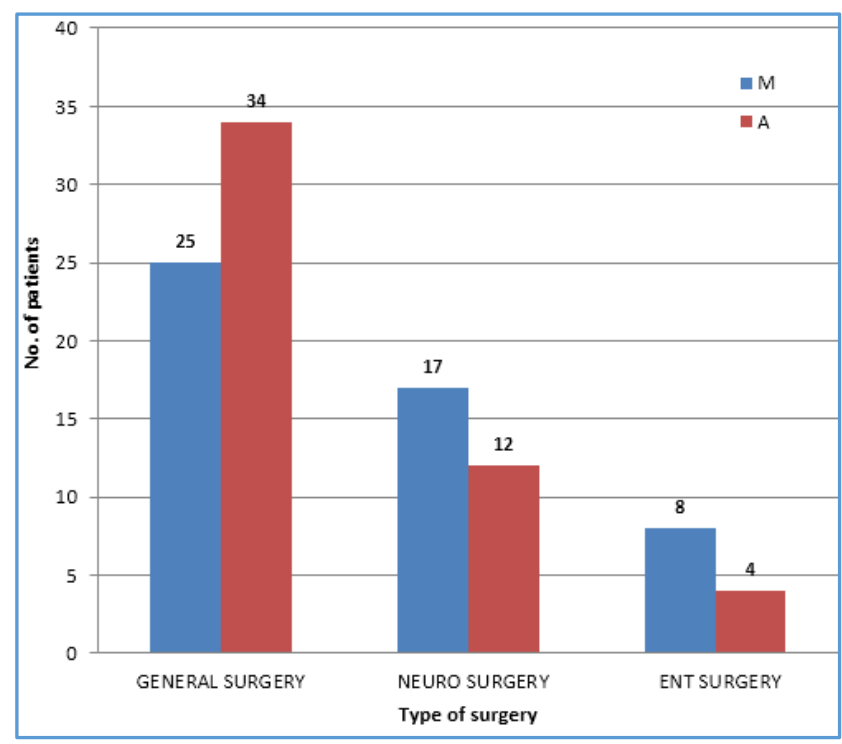

Graph 4. Distribution of Patients according to Nature of Surgical Procedures in Study Groups

\section{DISCUSSION}

Securing and maintenance of airway is one of the major responsibilities of an anaesthesiologist. The process of laryngoscopy is known to have profound cardiovascular effects. This includes pressor response and tachycardia along with an increase in catecholamine concentration mainly norepinephrine.

Obtundation of this reflex response remains a major concern for the anaesthesiologist. Deep anaesthesia, topical anaesthesia, Opioids, Calcium channel blockers, beta blockers, laryngeal mask airway and different types of laryngoscope blades have been tried with varying success.(1219)

It has been observed that amount of forces exerted during laryngoscopy and intubation is the key determinant for mechanical stimulation of stretch receptors present in the respiratory tract. Thus, use of different types of laryngoscope blades can help decreasing this response.(20)

In our study, we use Truview PCD videolaryngoscope, which is a new intubation device used for endotracheal intubation. It is designed to enable a view of glottis opening without aligning the oral with laryngeal and pharyngeal axis as an advantage over direct endotracheal intubation and allows intubation with minimal head manipulation and positioning.

\section{Demographic Data}

In the present study all the intubation were successfully performed in both the groups, which was in accordance with observation of various other studies.(21-24) However, some studies $(25,26)$ show higher success rate with videolaryngoscope as compared to Macintosh laryngoscope. The lower success rate in Macintosh group might be due to inclusion of Mallampati grade 1 and 2 patients.

Mean duration of intubation is also significantly higher with Truview laryngoscope than with Macintosh laryngoscope. Various other studies also supported this observation. $(23,26)$

The Truview required a midline entrance and difficulty with manipulation of tongue, which may prolong the duration of laryngoscopy and intubation with videolaryngoscope. Videolaryngoscope also requires a hand eye coordination for tracheal intubation, which might increase the intubation time observed.

The lower success rate in Macintosh group might be due to inclusion of Mallampati grade III and IV patients in their study, while our study included only Mallampati grade I and II patients.

\section{Haemodynamic Parameters \\ Heart Rate}

Laryngoscopy and intubation resulted in highly significant $(p<0.01)$ rise in heart rate in both the groups as compared to baseline. But the rise is more significant in Macintosh group as compared to videolaryngoscope group. In Group $M$, increase in pulse rate was statistically highly significant $(\mathrm{p}<0.01)$ at the time of laryngoscopy and ETI and $1 \mathrm{~min}, 2$ mins and 3 mins after ETI as compared to baseline and come to baseline at 5 mins after ETI.

Whereas in Group A, increase in heart rate is highly significant $(\mathrm{p}<0.01)$ at time of laryngoscopy and at $1 \mathrm{~min}$ after ETI. Thereafter, significant $(p<0.05)$ decrease in heart rate at 2 mins and highly significant $(\mathrm{p}<0.01)$ decrease in heart rate at 3 mins and 5 mins was observed as compared to baseline. The results were in accordance with observations of other studies. $(27,28)$

Videolaryngoscope does not require alignment of oral, pharyngeal and laryngeal axis and thus less manipulation and consequently less sympathetic stimulation, particularly in cases of difficult intubation which results in lesser haemodynamic changes as compared to Macintosh laryngoscope.

However, study conducted by Timanayankar RT et al(21) observed a significant rise in heart rate and systolic blood pressure under the stimulus of laryngoscopy and intubation in both the groups $(\mathrm{p}<0.05)$. They returned to near baseline values by 10 mins in both the groups, but the difference is insignificant $(p>0.05)$ in between the groups. 
Intergroup statistical analysis of mean $( \pm \mathrm{SD})$ systolic blood pressure $(\mathrm{mmHg})$ shows highly significant $(\mathrm{p}<0.01)$ decrease in mean $( \pm \mathrm{SD})$ systolic blood pressure in Group $A$ as compared to Group $\mathrm{M}$ at different time intervals.

The results were in accordance with observations of various other studies. $(29,30)$

Intergroup statistical analysis of mean $( \pm S D)$ diastolic blood pressure $(\mathrm{mmHg})$ shows insignificant $(\mathrm{p}>0.05)$ rise at the time of laryngoscopy and intubation and highly significant $(\mathrm{p}<0.01)$ fall in Group A as compared to Group M at different time intervals.

Study conducted by Jungbauer A et al(27) concluded that less rise in diastolic blood pressure in Truview group is due to the 42-degree slope in blade and also glottis view was obtained by applying approximate external force of 19.6 newton. While the pressure applied was more (32.3 newton) with Macintosh laryngoscope.

\section{Mean Blood Pressure}

Intergroup statistical analysis of mean $( \pm S D)$ blood pressure shows highly significant $(\mathrm{p}<0.01)$ decrease in mean blood pressure in Group A as compared to Group M at the time of laryngoscopy and thereafter.

Videolaryngoscope is associated with less rise in mean blood pressure since anterior view design of videolaryngoscope is associated with less lifting force at laryngoscopy and consequently an attenuated intubation response when compared to Macintosh laryngoscope.

Videolaryngoscope does not require alignment of oral, pharyngeal and laryngeal axis and do not need direct exposure of vocal cords and thus produces lesser haemodynamic changes due to reduction in lifting force necessary to obtain clear view of glottis.

No complications were observed with the use of either Macintosh laryngoscope or Videolaryngoscope. The Truview blade is designed to enable indirect laryngoscopic view, thus the anaesthetist applies less force on anterior larynx, resulting in fewer patients with bleeding and soft tissue damage. A study conducted by Jungbauer et al(27) observed trauma to gums and teeth with use of Macintosh laryngoscope, as they have included Mallampati group III and IV patients in their study.

No complications or trauma to soft tissue structures and teeth observed in our study might be due to exclusion of Mallampati grade III and IV patients from our study.

\section{Limitations of our Study}

A number of Important Limitations Exist regarding this Study like-

- Our study was not blinded.

- Results seen may differ in the hands of less experienced users.

- $\quad$ Mallampati grade III and IV patients not included in our study.

- Factors other than laryngoscopy may have contributed to haemodynamic findings.

- The depth of anaesthesia or adequacy of muscle relaxation, which might affect haemodynamic changes were not monitored in our study.

\section{CONCLUSION}

When compared to Macintosh laryngoscope, videolaryngoscope significantly reduces variations in haemodynamic parameters like heart rate; systolic blood pressure; diastolic blood pressure and mean blood pressure after endotracheal intubation. Videolaryngoscope required significantly more time for intubation as compared to Macintosh laryngoscope.

\section{REFERENCES}

[1] Skinner P. "Unani-tibbi”. In: Fundukian LJ, edr. The gale encyclopedia of alternative medicine. $3^{\text {rd }}$ edn. Farmington Hills, Michigan: Gale Cengage 2008. Retrieved 6 September 2010.

[2] Smith P, Smith FJ, Becker PJ. Haemodynamic response to laryngoscopy with and without tracheal intubation. South Afr J Anaesth Analg 2008;14(3):23-6.

[3] Ghaus SM, Singh V, Kumar A, et al. A study of cardiovascular response during laryngoscopy and intubation and their attenuation by ultrashort acting $\mathrm{b}$ - blocker esmolol. Indian J Anaesth 2002;46(2):104-6.

[4] Singhal S, Neha. Haemodynamic response to laryngoscopy and intubation: comparison of McCoy and Macintosh laryngoscope. The Internet Journal of Anesthesiology 2007;17(1):1-5.

[5] Samad K, Khan F, Azam I. Hemodynamic effects of anesthetic induction in patients treated with beta and calcium channel blockers. Middle East J Anaesthesiol 2008;19(5):1111-28.

[6] Kanchi M, Nair HC, Banakal S, et al. Haemodynamic response to endotracheal intubation in coronary artery disease: direct versus video laryngoscopy. Indian J Anaesth 2011;55(3):260-5.

[7] Miller JD, Becker DP, Ward JD, et al. Significance of intracranial hypertension in severe head injury. J Neurosurg 1977;47(4):503-16.

[8] Salvalaggio MF, Rehme R, Fernandez R, et al. A comparative study between the laryngoscope and lighted stylet in tracheal intubation. Rev Bras Anestesiol 2010;60(2):138-43.

[9] Haidry MA, Khan FA. Comparison of hemodynamic response to tracheal intubation with Macintosh and McCoy laryngoscopes. J Anaesthesiol Clin Pharmacol 2013;29(2):196-9.

[10] Zhou Y, Jew K. A new laryngeal mask supraglottic airway device with integrated balloon line: a descriptive and comparative bench study. Med Devices (Auckland, NZ) 2016;9:383-8.

[11] Barak M, Philipchuck P, Abecassis P, et al. A comparison of the Truview blade with the Macintosh blade in adult patients. Anaesthesia 2007;62(8):82731.

[12] Hamill JF, Bedford RF, Weaver DC, et al. Lidocaine before endotracheal intubation: intravenous laryngotracheal. Anaesthesiology 1981;55(5):578-81.

[13] Kautto UM, Heinonen J. Attenuation of haemodynamic response to laryngoscopy and intubation: a comparison of two methods of topical anaesthesia. Acta Anaesthesiol Scand 1982;26(6):599-602. 
[14] Vucevic M, Purdy GM, Ellis FR. Esmolol hydrochloride for management of the cardiovascular stress responses to laryngoscopy and tracheal intubation. $\mathrm{Br}$ J Anaesth 1992;68(5):529-30.

[15] Yaku H, Mikawa K, Maekawa N, et al. Effects of verapamil on the cardiovascular responses to tracheal intubation. Br J Anaesth 1992;68(1):85-9.

[16] Wig J, Sharma M, Baichoo N, et al. Nicardipine and verapamil attenuate the pressor response to laryngoscopy and intubation. Can J Anaesth 1994;41(12):1185-8.

[17] Casati A, Fanelli G, Albertin A, et al. Small doses of remifentanil or sufentanil for blunting cardiovascular changes induced by tracheal intubation: a double blind comparison. Eur J Anaesthesiol 2001;18(2):108-12.

[18] Braude N, Clements EAF, Hodges UM, et al. The pressor response and laryngeal mask insertion - a comparison with tracheal intubation. Anaesthesia 1989;44(7):551-4.

[19] Wood ML, Forrest ET. The haemodynamic response to the insertion of the laryngeal mask airway: a comparison with laryngoscopy and tracheal intubation. Acta Anaesthesiol Scand 1994;38(5):510-3.

[20] Forbes AM, Dally FG. Acute hypertension during induction of anaesthesia and endotracheal intubation in normotensive man. Br J Anaesth 1970;42(7):61824.

[21] Raveendra US, Mehandale SG, Shetty SR, et al. Evaluation of the Truview TM EVO2 laryngoscope for nasotracheal intubation. Saudi J Anaesth 2012;6(4):398-402.

[22] Li JB, Xiong YC, Wang XL, et al. An evaluation of the TruView EVO2 laryngoscope. Anaesthesia 2007;62(9):940-3.

[23] Malik MA, O’Donoghue C, Carney J, et al. Comparison of the Glidescope, the Pentax AWS and the Truview EVO2 with the Macintosh laryngoscope in experienced anaesthetists: a manikin study. $\mathrm{Br} \mathrm{J}$ Anaesth 2009;102(1):128-34.
[24] Singh I, Khaund A, Gupta A. Evaluation of truview EVO2 laryngoscope in anticipated difficult intubation a comparison to Macintosh laryngoscope. Indian J Anaesth 2009;53(2):164-8.

[25] Saxena A, Madan M, Shrivastava U, et al. Role of the Truview EVO2 laryngoscope in the airway management of elective surgical patients: A comparison with the Macintosh laryngoscope. Indian J Anaesth 2013;57(3):276-81.

[26] Jungbauer A, Schumann $M$, Brunkhorst V, et al. Expected difficult tracheal intubation: a prospective comparison of direct laryngoscopy and video laryngoscopy in 200 patients. $\mathrm{Br} \mathrm{J}$ Anaesth 2009;102(4):546-50.

[27] Joseph J, Sequeira T, Upadya M. Comparison of the use of McCoy and TruView EVO2 laryngoscopes in patients with cervical spine immobilization. Saudi J Anaesth 2012;6(3):248-53.

[28] Bag SK, Kumar VRH, Krishnaveni N, et al. A comparative study between Truview (PCD) laryngoscope and Macintosh laryngoscope in viewing glottic opening and ease of intubation: a crossover study. Anesth Essays Res 2014;8(3):372-6.

[29] Tempe DK, Chaudhary K, Diwakar A, et al. Comparison of hemodynamic responses to laryngoscopy and intubation with Truview PCD ${ }^{\mathrm{TM}}$, McGrath ${ }^{\circledR}$ and Macintosh laryngoscope in patients undergoing coronary artery bypass grafting: a randomized prospective study. Ann Card Anaesth 2016;19(1):6875.

[30] Amita S, Hemlatha S, Kotekar N. Laryngoscopic view and cardiovascular response to intubation with Truview laryngoscope in comparison with Macintosh laryngoscope. International Journal of Scientific Research 2016;5(2):532-5. 